\title{
FERTILITY OF BULLS USED IN SMALLHOLDER DAIRY PRODUCTION IN A CROP-LIVESTOCK FARMING SYSTEM IN ZIMBABWE
}

\author{
N.T. Kusina ${ }^{1}$, S. Mberego ${ }^{1}$, E. Masama', H. Hamudikuwanda ${ }^{1}$, M. Ndengu ${ }^{2}$ and J. \\ Majoni $^{1}$
}

1- Animal Science Department, Faculty of Agriculture, University of Zimbabwe, P. O. Box MP 167, Mount Pleasant, Harare, Zimbabwe, 2-Department of Preclinical Veterinary Studies, Faculty of Veterinary Science, University of Zimbabwe, P. O. Box MP 167, Mount Pleasant, Harare, Zimbabwe

\section{SUMMARY}

The potential brceding abilities of bulls $(n=12)$ used in the sinallholder dairy scheme of NhariraLancashire in Chivu District, Zimbabwe were evaluated using standard breeding soundness examination (BSE) and semen evaluation procedures. The bulls comprised Red Dane and Red Dane crosses $(n=9)$, and the indigenous breed, the Mashona $(n=3)$. Breeding soundness examinations were conducted in April, August and December 1999. The proportion of normal sperm as indicated by normal morphology and motility (semen quality) was significantly lower during the hot dry month of August compared to collections in April and December. No bulls had major physical abnormalities and sperm motility was similar among all the bulls. However, scrotal circumference was significantly correlated $\left(r^{2}=0.6\right)$ with age and varied with breed. The Mashona bulls had lower $(P<0.05)$ scrotal circumferences than the Red Dane and/or Red Dane crosses. The results indicate that semen quality varied with season and this implies that these seasonal variations may influence conception rates in cows.

Keynords: Bulls, fertility, smallholders, Zimbabwe

\section{INTRODUCTION}

Long calving intervals often exceeding $\mathbf{5 0 0}$ days have been reported in smallholder dairy herds in Zimbabwe (Dube, 2000; Masama et al, 2000). This is indicative of poor cow reproductive performance considering that the ideal calving interval is 12 to 13 months (Hafez, 1993). The cause of the poor reproductive performance has been ascribed to poor fertility of the cows (Masama et al., 2000). However, bull fertility can also be poor. The effects of a single infertile bull are more devastating on herd reproductive performance than those of a single infertile cow. Nonetheless. farmers in the smallholder dairy sector keep and continue to use bulls of unknown fertility. Due to lack of information, the main objective of this study was to evaluatc the fertility of bulls used in the smallholder dairy scheme of Nharira-Lancashire.

\section{MATERIALS AND METHODS}

\section{Site description}

Nharira is a smallholder (communal) crop-livestock production farming area, while Lancashire is a smallscale commercial farming area. Both areas are engaged in dairy production and they supply milk to a central milk collection centre called Nharira-Lancashirc Dairy Centre. The study sites are located in a scmi-arid area situated about 170 to 200-km southcast of Harare in Mashonaland East Province. Nharira-Lancashire is on average $1460 \mathrm{~m}$ above sea level on latitude $19^{\prime \prime} 2^{\prime} \mathrm{S}$ and longitude $30^{\prime \prime} 35^{\prime} \mathrm{E}$. The mean annual rainfall received in the area is 600 to $700 \mathrm{~mm}$ and mean maximum and minimum temperatures are $25^{\circ} \mathrm{C}$ and $12^{\circ} \mathrm{C}$, respectively. The vegetation in Nharira consists of sparsely scattered trees and short browseable bushes of $A c a c i a s p$. In general, the natural pastures are overgrazed.

\section{Bull selection}

Twelve bulls used for breeding of the dairy herds owned by farmers who were participating in a DANIDA project were evaluated in this study. This was part of an on-going study that started in 1993. The bulls comprised Red Dane (40\%) and Red Dane crosses (35\%) and the remainder comprised Mashona bulls. The mean age of the bulls was $6 \pm 3$ years (range 2 to 11 years). 


\section{Animal nutrition and health management}

Farmers were allowed to manage their bulls according to the normal practice. without intervention from the researchers. All the bulls dépended on natural pasture for sustenance and there was no provision of supplementary feeding. Bulls were let out in the morning in the company of the beef herds and kraaled at night. Veterinary services were accessible and available from the local Veterinary Office.

\section{Measurements \\ Breeding soundness assessment}

Bull fertility was cvaluated by breeding soundness examination (BSE) procedures described by Elmore (1994). In this procedure, each bull was subjected to a complete examination that comprised clinical evaluation of the testes, visual and microscopic evaluation of semen and a thorough visual and physical examination of the entire animal.

Scrotal circumference

The scrotal circumference for each bull was determincd using a measuring tape placed round the widest section of the scrotum.

\section{Semen collection and evaluation}

Semen was collected by rectal massage. The total volume of the collection was recorded and immediately visually evaluated for colour, consistency, progressive sperm motility, sperm morphology and types of abnormalities using a field microscope. A drop of undiluted semen was taken from the sample and placed over a glass slide and observed under a microscope at x10 magnification to determine mass motility. Next, a sample of the semen was diluted in normal saline to $1: 10$ or 1:20, depending on sperm concentration. A drop of the diluted semen was then transferred to a microscope slide, a cover slip was placed over the drop of semen and the sample was then observed under a microscope for progressive motility at $\times 40$ magnification. In order to determine sperm morphology, a drop of undiluted or diluted semen was mixed 1:1 with negrosinocsin dye and a smear prepared on a glass slide and then observed for dead and live sperm as well as general morphology.

\section{Statistical analysis}

Descriptive statistics was used to summarise data on sperm motility, morphological abnormalities and scrotal circumference. The effects of breed, age, month of assessment and farming system on scrotal circumference, sperm motility and sperm morphology were analysed using the Mixed Model Procedure for repeated measurements of the Statistical Analysis System (SAS, 1998) as outlined by Littell and Henry (1998). Data that was in percentage form was transformed by the arcsine square root function to attain normality.

\section{RESULTS}

Results obtained on scrotal circumference are presented in Table 1. Scrotal circumference was significantly correlated $\left(r^{2}=0.6: \mathrm{P}<0.05\right)$ with age of the bull (Figure 1). Overall, the age of the bull significantly affected scrotal circumference. Mashona bulls had significantly lower $(P<0.05)$ scrotal circumferences than the Red Dane and/or Red Dane crosses.

Results on semen evaluation are shown in Table 1. Sperm motility was not affected by breed or age of the bull, month of semen collection or management system. There were no differences $(P>0.05)$ in semen quality among the different age groups of bulls sampled (Table 1). The overall patterns of changes and relationships between age, scrotal circumference, sperm motility and sperm morphology are shown in Figure 1 .

The proportion of abnormal sperm was higher $(\mathrm{P}<0.05)$ in collections in August compared to those in April and December. Morphologically normal sperm were significantly less in the semen samples taken in August than for those collected in both April and December and primary sperm abnormalities were significantly higher in August than in both April and December. In the semen samples taken in August, there were high incidences of primary and secondary sperm head abnormalities. In addition, semen samples from Lancashire had significantly higher $(\mathrm{P}<0.05)$ levels of morphologically normal sperm than those from Nharira. 
Table 1. Mean scrotal circumference and semen analysis results for Red Dane and Mashona bulls in April, August and December 1999

\begin{tabular}{llcccc}
\hline Breed & & \multicolumn{3}{c}{ Red Dane } & Mashona \\
\cline { 3 - 6 } $\mathrm{N}$ & & 3 & 2 & 2 & 2 \\
\hline Age (years) & & 4 & 6 & 8 & 4 \\
Scrotal circumference (cm) & April & $30.5 \pm 1.3$ & $32.8 \pm 0.3$ & $32.5 \pm 0.0$ & $28.0 \pm 1.4$ \\
& August & $31.3 \pm 1.8$ & $34.0 \pm 1.4$ & $33.5 \pm 0.7$ & $29.0 \pm 1.4$ \\
& December & $33.3 \pm 0.8$ & $38.0 \pm 0.0$ & $35.3 \pm 1.1$ & $30.3 \pm 1.8$ \\
Sperm motility (\%) & April & $43.3 \pm 30.6$ & $50.0 \pm 0.0$ & $55.0 \pm 7.1$ & $90.0 \pm 7.1$ \\
& August & $57.5 \pm 3.5$ & $50.0 \pm 0.0$ & $52.5 \pm 17.7$ & $37.5 \pm 24.7$ \\
Normal sperm (\%) & December & $63.3 \pm 15.3$ & $59.0 \pm 36.8$ & $45.0 \pm 0.0$ & $72.5 \pm 3.5$ \\
& April & $82.8 \pm 5.7$ & $81.0 \pm 11.3$ & $65.5 \pm 13.4$ & $68.3 \pm 41.4$ \\
& August & $40.5 \pm 6.4$ & $34.0 \pm 5.6$ & $39.5 \pm 20.5$ & $37.5 \pm 3.5$ \\
Primary abnormalities (\%) & December & $85.0 \pm 6.2$ & $55.0 \pm 41.8$ & $82.0 \pm 2.8$ & $76.5 \pm 17.6$ \\
& April & $4.3 \pm 3.6$ & $11.1 \pm 9.7$ & $9.8 \pm 3.0$ & $2.2 \pm 1.9$ \\
& August & $29.7 \pm 12.7$ & $12.7 \pm 31.3$ & $31.4 \pm 2.1$ & $13.6 \pm 18.7$ \\
& December & $2.0 \pm 1.9$ & 0 & $3.1 \pm 4.3$ & $3.1 \pm 4.3$ \\
\hline
\end{tabular}

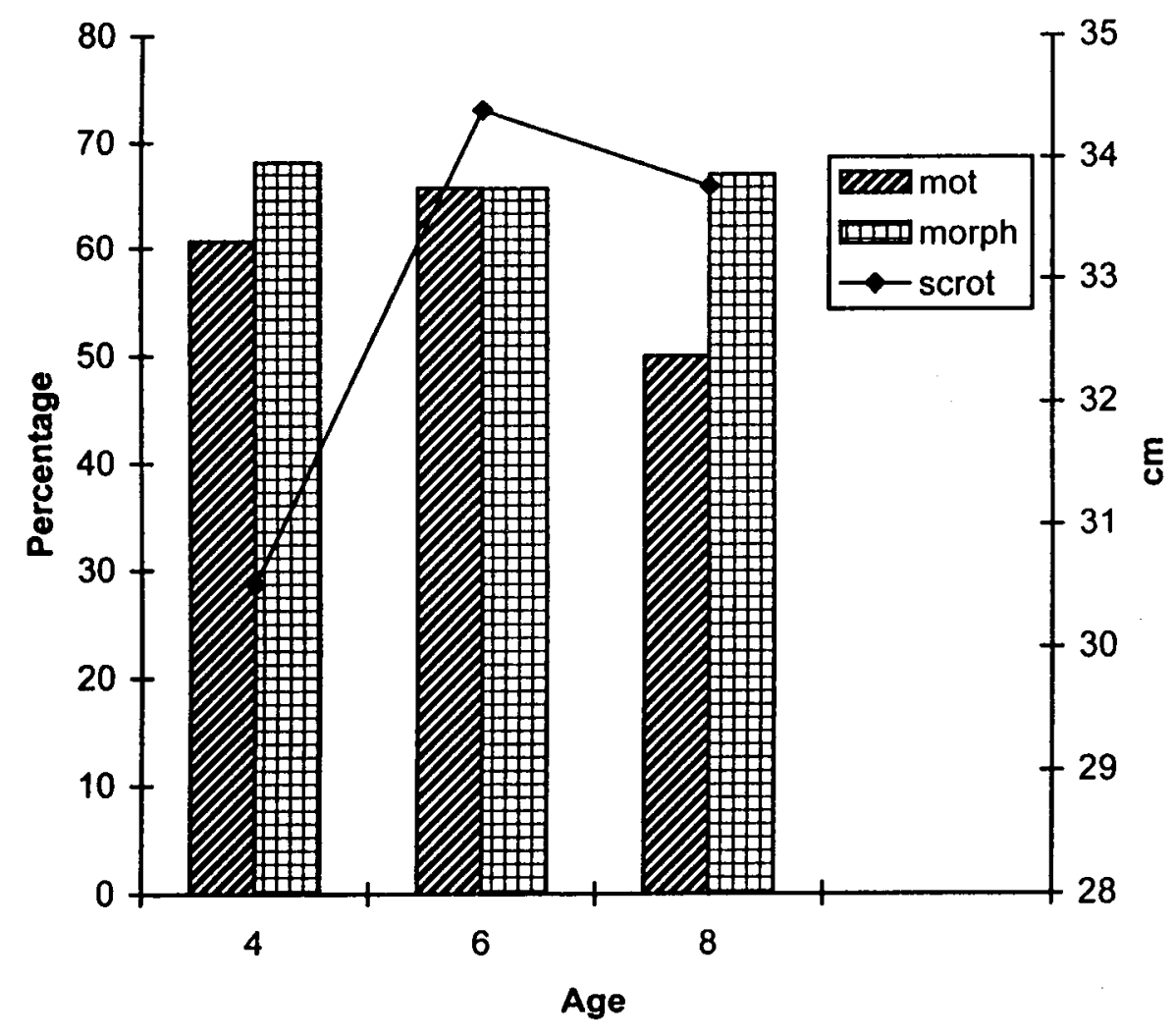

Figure 1. Testicular circumference and spermatozoa motility and morphology in relation to age in Zimbabwe cattle breeds 


\section{DISCUSSION}

To our knowledge this is the first study in Zimbabwe that has been undertaken to evaluate fertility of bulls used in smallholder dairy agriculture. Assessment of breeding soundness of the bulls would be an important tool in selecting good quality bulls that in turn might improve overall cow fertility. From the study: the proportion of morphologically normal sperm with good progressive motility was lower in August. a hot dry month. compared to collections laken in April and December. Primary sperm abnormalitics were higher in August than the other two months. The observed increased proportion of morphologically abnormal spcrm cells could be attributed to a number of factors such as inadequate animal health care and nutritional management as well as environmental challenges.

In this study. bulls were not given any form of supplementary feed throughout the year. In contrast 10 milking cows. bulls derived sustenance from pasture alone. In Nharira-Lancashire and other communal areas, natural pasture detcriorates in quality and quantity during the dry season (Topps, 1977; Chimonyo et al., 1999). From May to October, cattle in communal areas lose weight and body condition due to inadequate and poor feed supply. Invariably, productivity is also adversely affected. It is. therefore. highly likely that poor nutrition compromised semen quality manifested by the high proportion of morphologically abnormal sperm in August compared to April and Decomber. In both April and December. Feed is relatively abundant in the form of crop residues in April and green lush vegetation rejuvenated by the early rains in December.

The nutritional management of the bull is of paramount importance in determining short-term and longterm performance. Nutritional stress or undernutrition early in the life of the bull calf delays attainment of puberty and in severe cases may even cause irreversible testicular damage. In mature bulls, undernutrition may impair the ability to travel, decrease sperm production and libido (Carpenter, 1999). However, generous feeding of the bull leading to accumulation of excessive fat will also produce similar effects on libido (Carpenter, 1999). On the other hand, improvement in sperm production following supplementary feeding of copper. cobalt. manganese and zinc has been reported while vitamin A deficiency has been found to cause icsticular degeneration (Hafez. 1993). It is important, therefore, that the nutrition of the bull be optimal, not cxecssive nor deficient. This is a prerequisite for optimum fertility and performance.

In addition to the effects of nutritional stress. environmental stresses such as high temperatures and their interiution could lave been detrimental to normal spermatogenesis and probably contributed to uhe appearance of a high proportion of morphologically abnormal sperm in August. During the dry season in Nharira-Lancashire, temperatures can soar beyond $30^{\circ} \mathrm{C}$. This can be expected to result in temporary bull infertility due to the fact that heat stress causes a transient increase in morphologically abnormal spermato/oal and a subsequent decrease in fertility. Abnormal sperm appear in the ejaculate approximately two weeks following heat stress and normal morphology will return after about three months (Elmore, 1985). Heat stress causes temporary infertility due to the damage of one of the meiotic thermo-sensitive cells during spermatogenesis rendering such sperm infertile (Arthur et al., 1996). Although difficult to control, under normal communal farming systems, bulls will seek shade when it is hot. However it is also important that farmers provide shade in view of the degradation and lack of adequate tree cover. particularly in Nharira.

In conclusion. semen characteristics particularly the proportion of abnomal sperm was different among the three months of April, August and December. The proportion of abnormal sperm was significantly higher in August than during the other months. Breed and age of bulls were related to scrotal circumference. Orerall. these results suggest that the month and the associated changes, especially temperature and the availability of fecd. influence some fertility characteristics in bulls in the smallholder dairy sector. More work necds to be done to detennine fertility levels across all months of the year and the possible influence of nutrition and season related measurements such as temperature.

\section{ACKNOWLEDGEMENTS}

The authors would like to recognize the financial assistance from UZ/RVAU/DANIDA ENRECA. Zimbabwe. We are also grateful to all field officers and farmers who participated in this sludy.

\section{REFERENCES}

Arthur. H.G.. Naakcs. D.E. and Parkingson T.J., 1996. Veterinary Reproduction and Obstetrics, Saunders Company Ltd. London.

Carpenter. B.. 1999. Proccedings of the Cattle Producers Association Cattle Management School, Cattle Management Association of Zimbabwc. pp. 30-36. 
Chimonyo, M., Kusina, N.T., Hamudikuwanda, H. and Nyoni, O., 1999. Journal of Applied Sciences for Southern Africa $5: 111-121$.

Dube, D., 2000. Paper presented at the UZ/RVAU/DIAS/DANIDA-ENRECA Project Workshop, 10-13 January, Harare, Zimbabwe. 15 pp.

Elmore, R.G., 1985. Veterinary Medicine 80: 80-84.

Elmore, R.G., 1994. Veterinary Medicine 89: 372-378.

Hafez, E.S.E., 1993. Reproduction in Farm Animals. Lea and Feibiger. Philadelphia.

Little, R.C. and Henry, P.R, 1998. Journal of Animal Science 76: 1216-1231.

Masama, E.. Kusina, N.T. Sibanda, S. and Majoni. J. 2000. Tropical Animal Health and Production (submitted).

Mupunga, E.G. 1993. Proceedings of Workshop on Integrated Livestock/Crop production Systems in Zimbabwe. University of Zimbabwe. pp. 11-14.

Topps, J. 1977. World Review of Animal Production XIII: 43-49. 